DE

M E D I C I N A

T R O P I C A L

$\mathrm{DE}$

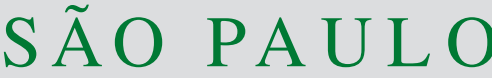

JOURNAL OF THE SÃO PAULO INSTITUTE OF TROPICAL MEDICINE

(1) Aga Khan University, Department of Biological and Biomedical Sciences, Karachi, Pakistan

(2) Sunway University, Faculty of Science and Technology, Department of Biological Sciences, Malaysia

Correspondence to: Naveed Ahmed Khan Sunway University, Faculty of Science and Technology, Department of Biological Sciences, 47500, Selangor, Malaysia Tel: 60-(0)3-7491-8622, Ext: 7176.

Fax: 60-(0)3-5635-8630

E-mail: naveed5438@gmail.com

Received: 10 August 2016

Accepted: 22 February 2017

\section{Presence of rotavirus and free-living amoebae in the water supplies of Karachi, Pakistan}

\author{
Farzana Abubakar Yousuf ${ }^{1}$, Ruqaiyyah Siddiqui ${ }^{2}$, Naveed Ahmed Khan ${ }^{2}$
}

\section{ABSTRACT}

Rotavirus and pathogenic free-living amoebae are causative agents of important health problems, especially for developing countries like Pakistan where the population has limited access to clean water supplies. Here, we evaluated the prevalence of rotavirus and free-living amoebae (Acanthamoeba spp., Balamuthia mandrillaris, Naegleria fowleri) in drinking water supplies of Karachi, Pakistan. Six water filtration plants that supply drinking water to the population of Karachi were investigated. Additionally, drinking water samples from households were analyzed for the presence of rotavirus and free-living amoebae. Rotavirus was present in $35 \%$ of the water samples collected from water filtration plants; however, domestic tap water samples had a prevalence of only 5\%. Out of 20 water samples from filtration plants, $13(65 \%)$ were positive for Acanthamoeba spp., and one (5\%) was positive for B. mandrillaris. Out of 20 drinking water samples collected from different areas of Karachi, $35 \%$ were positive for Acanthamoeba spp. Rotavirus was detected in 5\% of the drinking water samples tested. Overall, these findings showed for the first time the presence of rotavirus, in addition to pathogenic free-living amoebae in drinking water supplies of Karachi that could be an important public health risk for the affected population.

KEYWORDS: Rotavirus. Acanthamoeba. Naegleria. Balamuthia mandrillaris.

\section{INTRODUCTION}

Aquatic environments serve as a reservoir for enteric viruses, free-living amoebae and bacterial pathogens. If treated ineffectively, drinking water supplies pose a serious risk to public health ${ }^{1-3}$. Among viruses, species of the genus rotavirus are recognized as one of the leading viruses causing diarrhea in infants and children. Rotavirus is a double-stranded RNA virus with icosahedral symmetry. Based on their genetic and antigenic properties, seven species (A to $G$ ) of rotaviruses have been defined. Among these, rotavirus $A$ accounts for more than $90 \%$ of gastroenteritis in humans worldwide 4 . Recently, oral rotavirus vaccine has been introduced in several countries using attenuated rotaviruses limiting the number of cases by more than $70 \%$, however it is not part of routine immunization in several countries including Pakistan. The virus is highly transmissible from contaminated surfaces and it could survive up to several weeks or months ${ }^{5}$. Free-living amoebae are common inhabitants of our ecological environment, e.g., soil and water. Given the opportunity and host susceptibility, pathogenic free-living amoebae can cause serious and sometimes fatal infections. These include primary amoebic meningoencephalitis due to Naegleria fowleri; granulomatous amoebic encephalitis due to pathogenic Acanthamoeba spp. and Balamuthia mandrillaris, as well as a blinding keratitis due to pathogenic Acanthamoeba spp $^{6}$. In addition, several lines of evidence suggest 
that amoebae harbor bacterial and viral pathogens, and help them to survive, propagate and colonize, thus contributing to their transmission to susceptible hosts ${ }^{7}$.Verani et $a .^{8}{ }^{8}$ showed that A. polyphaga provides protection to human adenoviruses in natural environments, the latter, in turn, can cause a variety of infections. In this regard, infections by amoebae-associated pathogens, as demonstrated by the presence of amoebae as well as rotavirus are a potential risk to public health. This is of particular concern as developing countries such as Pakistan face serious fresh water shortage and increased public reliance on water storage tanks and wells. Among a plethora of pathogens, here we investigated the prevalence of rotavirus and representative free-living amoebae (Acanthamoeba spp., B. mandrillaris, N. fowleri) in the water filtration plants that supply drinking water to the population of Karachi, and drinking water samples from households. It is hypothesized that rotavirus and freeliving amoebae co-exist in the drinking water supplies in a symbiotic relationship.

\section{MATERIAL AND METHODS}

\section{Study location and water sampling}

There are six different water filtration plants that supply drinking water to the city of Karachi, Pakistan, and all were analyzed (Figure 1). These included water samples from Keenjhar Lake and its associated filtration plant (Keenjhar extreme Inlet, K.G. canal outlet, K.B. Feeder inlet point), Gharo filtration plant, Pipri filtration plant, NEK old filtration plant, COD filtration plant and NEK II filtration plant. Water samples were collected from February to July 2014, on a monthly basis. Apart from NEK old filtration plant and NEK II filtration plant, water samples were collected at three points of filtration i.e., inlet, intermediate, and post-treatment samples. From each testing site, two liters of water sample were collected in sterile water bottles and kept at $4{ }^{\circ} \mathrm{C}$ until analyzed, within one week.

Two liter water samples were collected from domestic tap water supplies in sterile bottles. A total of 20 samples were collected from different areas of Karachi from May to July 2014. All the 20 samples were randomly selected from various locations of Karachi city. Each sample was collected in a polypropylene bottle, and stored at $4{ }^{\circ} \mathrm{C}$ until subsequent analysis, within one week.

\section{Processing of rotavirus samples}

One liter of water sample was filtered through a sterilized positively charged 47 -diameter Sartolon polyamide $0.45 \mu \mathrm{m}$ pore size filter (Sartorius, Goettingen) under vacuum. After

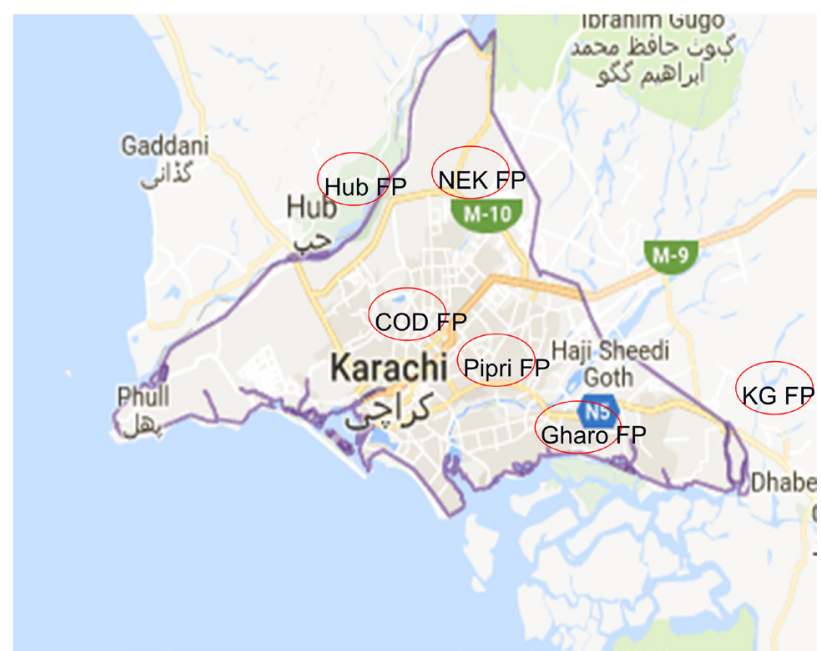

Figure 1 - Map showing water collection sites for water filtration and supply to the city of Karachi, Pakistan

filtration, the filter paper was placed in a sterile Petri dish. Viruses were eluted in Tris-glycine buffer containing $1 \%$ of beef extract ( $\mathrm{pH} 9.5)$ with brief horizontal shaking $(100 \mathrm{x} \mathrm{g})$ for $20 \mathrm{~min}$. at room temperature. The eluate was neutralized with $1 \mathrm{~N} \mathrm{HCl}$ and centrifuged for $1 \mathrm{~h}$ at $13,000 \mathrm{xg}$ at $4{ }^{\circ} \mathrm{C}$. The supernatant was removed and the pellet was resuspended in $200 \mu \mathrm{L}$ of sterile PBS and stored at $-80{ }^{\circ} \mathrm{C}$ until the analysis ${ }^{9}$. The extracted virus particles were screened for the presence of rotavirus antigen with a commercially available enzyme-linked immunosorbent assay (ELISA) kit (ProSpecT Rotavirus Kit, Oxoid Company, UK) as per manufacturer's instructions. The sandwich enzyme immunoassay (ELISA) kit contains a polyclonal antibody on a solid-phase to detect the presence of rotavirus A antigen (ProSpecT Rotavirus Kit Oxoid). The extracted virus particles as well as positive and negative control samples provided in the kit, were added and incubated with rotavirus $A$ antigen-specific polyclonal antibody, conjugated to horseradish peroxidase. The microwell plate was incubated at room temperature for $1 \mathrm{~h}$. Next, microplates were washed with washing buffer to remove the excess specimen and any unbound enzyme labeled antibody. A chromogen was added and plates incubated for $10 \mathrm{~min}$ at room temperature. The presence of specifically-bound enzyme labeled antibody in the micro wells resulted in a color change. The reaction was stopped by adding acetic acid, and the absorbance was read at $450 \mathrm{~nm}$. The values $\geq 0.15$ were considered positive for rotavirus $A$ antigen.

Isolation and identification of Acanthamoeba spp., Naegleria fowleri and Balamuthia mandrillaris in water samples

An additional one liter of water sample was filtered through a sterilized $0.45 \mu \mathrm{m}$ pore size cellulose filter under 
vacuum. The filters were inverted on to $1.5 \%$ non-nutrient agar plates containing a lawn of heat-inactivated E. coli K-12 laboratory strain, HB101 as previously described ${ }^{10}$. Plates were incubated at $35^{\circ} \mathrm{C}$, then daily examined for the presence of amoebae using a phase-contrast microscope, for up to 3 weeks. As a positive control, approximately 10,000 amoebae were added to sterile distilled water in a 1 liter bottle and processed as above. The identity of amoebae was confirmed using polymerase chain reaction (PCR). Briefly, DNA was extracted using Instagene matrix (BioRad) according to the manufacturer's instructions. The supernatant containing DNA ( 1 ng) was used as the template for PCR and analyzed for the presence of Acanthamoeba spp., N. fowleri and B. mandrillaris using specific primers, as described previously ${ }^{11}$. The primer sequence for Acanthamoeba spp., yielded an amplicon of $910 \mathrm{bp}^{12}, N$. fowleri yielding an amplicon of $153 \mathrm{bp}^{13}$ and B. mandrillaris yielding an amplicon of $171 \mathrm{bp}^{14}$ are indicated in Table 1.

\section{RESULTS AND DISCUSSION}

Enzyme-linked immunosorbent assay (ELISA) demonstrated the presence of rotavirus antigen in water treatment plant samples and drinking water supplies

For the first time in Pakistan, water samples from various water filtration plants, as well as water samples from drinking water supplies, were analyzed for the presence of rotavirus $A$ antigen. Among 20 water samples obtained from six different water filtration plants in Karachi, rotavirus antigen was detected in seven out of 20 samples (35\%) (Figure 2, Table 2). Although rotavirus antigen was found in raw and inlet water samples, post-treatment water samples from Keenjhar Lake filtration plant, Gharo filtration plant, Pipri filtration plant, NEK old filtration plant and NEK II filtration plant did not show the presence of rotavirus antigens. However, water samples collected from COD filtration plant showed the presence of rotavirus antigens in inlet, intermediate, as well as post-treatment water samples. Twenty tap water samples from households were also collected from drinking water supplies in different regions of Karachi, and analyzed. Rotavirus antigen was detected in one water sample out of $20(5 \%)$ drinking water samples tested (Table 2). When data were grouped for each plant, it was noteworthy that only two plants out of six were able to clean the rotavirus contamination. Thus, these data may explain the lower prevalence of rotavirus antigen in tap water as compared to the water collected from the treatment plants.

Presence of free-living amoebae in samples from water filtration plants and drinking water supplies of Karachi

The water samples collected from six water treatment plants were tested for the presence of free-living amoebae (Acanthamoeba spp., N. fowleri and B. mandrillaris) using PCR. Out of 20 water samples from filtration plants, $13(65 \%)$ were positive for Acanthamoeba spp., and 1 (5\%) was positive for B. mandrillaris (Table 2). All the samples tested negative for $N$. fowleri. Out of 20 drinking water samples collected from different areas of Karachi, 7 (35\%) were positive for Acanthamoeba spp., however all drinking water samples were negative for $N$. fowleri and B. mandrillaris (Table 2).

Drinking water supplied to the population of Karachi is sourced from Keenjhar Lake and carried to water treatment plants for setting, filtration and chlorination. Subsequently, water is distributed to the local population of Karachi. Keenjhar Lake is situated in the Thatta district, Sindh, and is one of the main sources of water $(900$ cubic feet per second per day) through which drinking water is supplied to Karachi, albeit intermittently. It is estimated that $>30,000$ people, out of whom 20,000 are children, die every year due to diarrheal diseases in Karachi alone because of unsafe water ${ }^{15-17}$. Among diarrheal pathogens, rotavirus is the leading cause of morbidity and mortality in children $^{18-20}$. For the first time in Pakistan, we showed the

Table 1 - The primer pairs used in the present study to identify Acanthamoeba spp., Naegleria fowleri and Balamuthia mandrillaris

\begin{tabular}{ll}
\hline & Primer sequence \\
\hline Acanthamoeba spp. & AcanF (5'-TTTGAATTCGCTCCAATAGCGTATATTAA-3') \\
& AcanR (5'-TTTGAATTCAGAAAGAGCTATCAATCTGT-3') \\
Naeglaria fowleri & NaeglF192 (5'-GTGCTGAAACCTAGCTATTGTAACTCAGT-3') \\
& NaegIR344 (5'-CACTAGAAAAAGCAAACCTGAAAGG-3') \\
Balamuthia mandrillaris & BalaF1451 (5'-TAACCTGCTAAATAGTCATGCCAAT-3') \\
& BalaR1621 (5'-CAAACTTCCCTCGGCTAATCA-3') \\
\hline
\end{tabular}




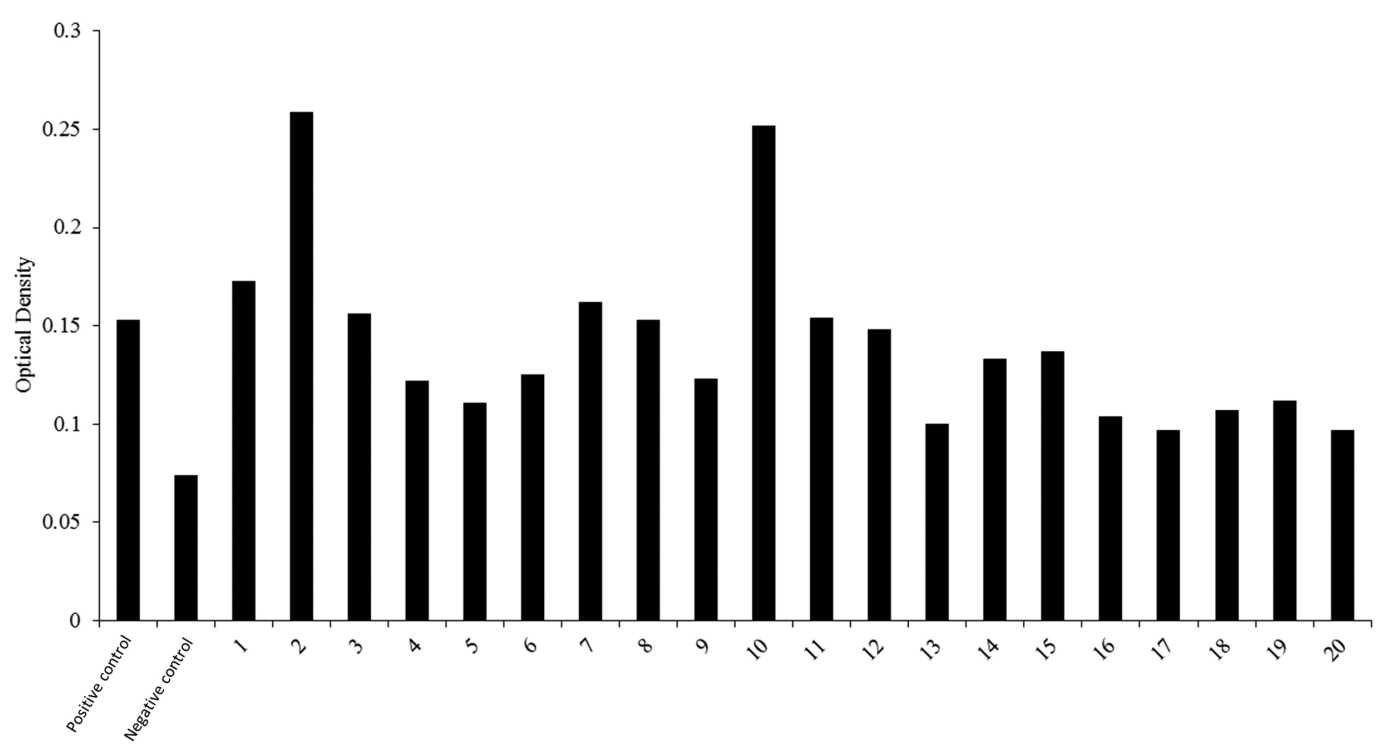

Figure 2 - Water samples from different filtration plants (Keenjhar, Gharo, Pipri, NEK old, COD and NEK II filtration plants) were collected between February and July, 2014, and tested for the presence of rotavirus $A$ antigen, as described in Materials and Methods. The values $\geq 0.15$ were considered positive for rotavirus antigen

Table 2 - Distribution of rotavirus and free-living amoebae in six water filtration plants that supply drinking water to the population of Karachi, Pakistan

\begin{tabular}{|c|c|c|c|}
\hline Sr. & Water source & Rotavirus & Free-living amoebae \\
\hline 1 & COD plant (inlet water sample) & Positive & Negative \\
\hline 2 & COD plant (intermediate-treatment) & Positive & Negative \\
\hline 3 & COD plant (post-treatment) & Positive & Acanthamoeba \\
\hline 4 & Pipri plant (inlet) & Negative & Negative \\
\hline 5 & Pipri plant (intermediate) & Negative & Negative \\
\hline 6 & Pipri plant (post-treatment) & Negative & Acanthamoeba/ Balamuthia \\
\hline 7 & Gharo plant (inlet) & Positive & Acanthamoeba \\
\hline 8 & Gharo plant (intermediate) & Positive & Acanthamoeba \\
\hline 9 & Gharo plant (post-treatment) & Negative & Acanthamoeba \\
\hline 10 & Keenjhar plant (inlet) & Positive & Negative \\
\hline 11 & Keenjhar plant (intermediate) & Positive & Negative \\
\hline 12 & Keenjhar plant (post-treatment) & Negative & Negative \\
\hline 13 & NEK old plant (raw) & Negative & Acanthamoeba \\
\hline 14 & NEK old plant (inlet) & Negative & Acanthamoeba \\
\hline 15 & NEK old plant (intermediate) & Negative & Acanthamoeba \\
\hline 16 & NEK old (post-treatment) & Negative & Acanthamoeba \\
\hline 17 & NEK II plant (raw) & Negative & Acanthamoeba \\
\hline 18 & NEK II plant (inlet) & Negative & Acanthamoeba \\
\hline 19 & NEK II plant (intermediate) & Negative & Acanthamoeba \\
\hline 20 & NEK II plant (post-treatment) & Negative & Acanthamoeba \\
\hline
\end{tabular}

presence of rotavirus in $35 \%$ of water samples collected from water filtration plants, as well as $5 \%$ of water samples collected from drinking water supplies. In comparison, rotavirus was detected in $1.4 \%$ of drinking water samples analyzed in Pretoria, South Africa, and $11.8 \%$ of water samples collected from water purification plants ${ }^{21}, 2 \%$ of water samples in Slovenia ${ }^{22}$, while in China, rotavirus was detected in $34.6 \%$ of raw water drawn samples from 
the source; $11.7 \%$ of treated water samples and $22.4 \%$ of tap water samples from different areas of Beijing ${ }^{23}$, albeit different methodologies were used to detect rotavirus. Rotavirus was detected in up to $62.5 \%$ of water samples collected from filtration plants ${ }^{18}$, while $37.5 \%$ of water samples were positive for rotavirus in drinking water samples in Columbia; $48.1 \%$ of tested water samples were positive for rotavirus, in Ghana ${ }^{24}$. Notably, our study used ELISA to detect rotavirus antigen and it is limited to water samples collected from filtration plants, as well as households that were supplied with treated water by the local Karachi Water and Sewage Board. This excludes many slums and other areas of Karachi. A large disadvantaged population of Karachi relies on water through tanker and other sources that are often untreated, which is the subject of future studies. Future studies should investigate water samples supplied to a larger population of Karachi as well as seasonal distribution of microbial contaminants, which will provide the accurate account of prevalence of pathogenic microbes in the drinking water supplies of Karachi. Several lines of investigations showed an association between the occurrence of rotavirus infection and weather conditions. Rotavirus infection rates were high in the winter season, compared with the summer season in the USA ${ }^{19}$, Japan ${ }^{25}$, Northern Asian regions ${ }^{20}$, temperate regions in Australia ${ }^{26}$ and Europe ${ }^{27}$. In moderate climate regions, a peak in rotavirus infection was often observed in colder and drier months of the year ${ }^{28}$. A comprehensive study on the seasonal distribution of rotavirus in drinking water supplies of Karachi and the number of rotavirus-associated diarrheal cases in local hospitals throughout the year will determine the effectiveness of the present water treatment practices.

Our study also showed that up to $65 \%$ of water samples were positive for Acanthamoeba spp. and 5\% of water samples were positive for $B$. mandrillaris from water collected from filtration plants, while $35 \%$ of drinking water samples were positive for Acanthamoeba spp. Notably, when the contamination was already present in the incoming water (three plants out of six), none of the analyzed plants were able to reduce it. Moreover two plants out of six (i.e., COD and Pipri, Table 2) showed Acanthamoeba spp. and/ or B. mandrillaris contamination in the outcoming, but not in the incoming water. These findings suggest that source of amoebae contamination is post-treatment, which should be investigated in further studies. This is in accordance with the high prevalence of Acanthamoeba spp. (35\%) found in the tap water samples. These results are consistent with previous findings which showed the prevalence of freeliving amoebae in $38 \%$ of the water samples tested ${ }^{11}$. For example, in Sivas, Turkey, free-living amoebae were found in $30 \%$ of drinking water samples ${ }^{29}$, while water samples in Nicaragua had a prevalence of $21 \%$ of Acanthamoeba spp. in drinking water supplies ${ }^{30}$. Acanthamoeba are known to predate and/ or harbour viruses, bacteria, protists and are often referred to as the Trojan horse of the microbial world ${ }^{7}$. Supporting this idea, recent studies have tested the interaction between A. polyphaga and human adenovirus to determine whether the amoeba play a role in protecting the internalized viruses from chemical disinfection. The results revealed that when amoeba and human adenovirus were co-cultured, infectious viruses were more resistant to disinfection suggesting that $A$. polyphaghas provided protection for human adenovirus. Based on these findings, it is tempting to speculate that there is association between Acanthamoeba and rotavirus. Notably, recent studies have suggested that rotavirus internalization of $A$. castellanii occurs only via infected mammalian cells, but not of freely suspended virus ${ }^{31}$. The precise rotavirus association with Acanthamoeba and the potential implications of amoeba to harbour viruses during its cyst stage to protect against water disinfection strategies, as well as to help their transmission to susceptible populations, is an interesting hypothesis which will be the subject of future studies. Moreover, it can be speculated that viruses ingested by Acanthamoeba can be incorporated by protists into biofilms and survive within this protected niche environment. Upon environmental stimuli, viruses may escape from the biofilm, representing a potential threat. It is also possible that rotavirus replicate within the infected protist, or that multiplication of protists may lead to increased progeny of the virus, thus increasing the potential for virus spread. Overall, this study has underlined the need for additional investigations of aquatic environments, in addition to drinking water supplied to larger population of Karachi, to detect rotavirus strains and free-living amoebae circulating in the community, their seasonal distribution and possible associations during various stages of the life cycle of Acanthamoeba. The effective management of public water supplies and the implementation of proper precautionary regulatory actions will assist in the prevention of serious diseases caused by rotavirus and pathogenic protists or resulting from their symbiotic hyperparasitic roles.

\section{ACKNOWLEDGEMENTS}

The authors are grateful for the kind support provided by the Aga Khan University, Pakistan and the Sunway University, Malaysia. The authors are grateful to Syed Usman Bin Mahmood, Atteeba Manzar, Ammar Alam for their technical support. 


\section{CONFLICTING INTERESTS}

The authors declare no competing interests.

\section{AUTHORS' CONTRIBUTION}

NAK conceived the study. YFA and RS designed the experiments. All experiments were performed by YFA under the supervision of RS and NAK. YFA performed the analyses and interpretations. YFA wrote the first draft of the manuscript. RS and NAK corrected the manuscript. All of the authors approved the manuscript.

\section{ETHICAL APPROVAL}

Not applicable.

\section{REFERENCES}

1. Fong TT, Lipp EK. Enteric viruses of humans and animals in aquatic environments: health risks, detection, and potential water quality assessment tools. Microbiol Mol Biol Rev. 2005;69:357-71.

2. World Health Organization. Water sanitation hygiene: diseases. [cited 2016 Oct 04]. Available at: http://www.who.int/water_ sanitation_health/diseases-risks/diseases/en/

3. Centers for Disease Control and Prevention. Water-related diseases and contaminants in public water systems. [cited 2016 Sept 23]. Available from: http://www.cdc.gov/healthywater/drinking/ public/water_diseases.html

4. Desselberger U. Rotaviruses. Virus Res. 2014;190:75-96.

5. Dennehy PH. Rotavirus infection: an update on management and prevention. Adv Pediat. 2012;59:47-74.

6. Visvesvara GS, Moura H, Schuster FL. Pathogenic and opportunistic free living amoebae: Acanthamoeba spp., Balamuthia mandrillaris, Naegleria fowleri and Sappinia diploidea. FEMS Immunol Med Microbiol. 2007;50:1-26.

7. Khan NA. Acanthamoeba: biology and pathogenesis. $2^{\text {nd }}$ ed. Norfolk: Caister Academic Press; 2015.

8. Verani M, Di Giuseppe G, Tammaro C, Carducci A. Investigating the role of Acanthamoeba polyphaga in protecting Human Adenovirus from water disinfection treatment. Eur J Protistol. 2016;54:11-8.

9. Steyer A, Torkar KG, Gutiérrez-Aguirre I, Poljšak-Prijatelj M. High prevalence of enteric viruses in untreated individual drinking water sources and surface water in Slovenia. Int J Hyg Environ Health 2011;214:392-8.

10. Brindley N, Matin A, Khan NA. Acanthamoeba castellanii: high antibody prevalence in racially and ethnically diverse populations. Exp Parasitol. 2009;121:254-6.

11. Yousuf FA, Siddiqui R, Subhani F, Khan NA. Status of free-living amoebae (Acanthamoeba spp., Naegleria fowleri, Balamuthia mandrillaris) in drinking water supplies in Karachi, Pakistan. J Water Health 2013;11:371-5.

12. Kong HH, Chung DI. PCR and RFLP variation of conserved region of small subunit ribosomal DNA among Acanthamoeba isolates assigned to either A. castellanii or A. polyphaga. Korean J Parasitol. 1996;34:127-34.

13. Shakoor S, Beg MA, Mahmood SF, Bandea R, Sriram R, Noman F, et al. Primary amebic meningoencephalitis caused by Naegleria fowleri, Karachi, Pakistan. Emerg Infect Dis. 2011;17:258-61.

14. Qvarnstrom Y, Visvesvara GS, Sriram R, da Silva AJ. Multiplex real-time PCR assay for simultaneous detection of Acanthamoeba spp., Balamuthia mandrillaris, and Naegleria fowleri. J Clin Microbiol. 2006;44:3589-95.

15. World Wildlife Fund. Pakistan's waters at risk: water \& health related issues in Pakistan \& key recommendations. Lahore: WWF; 2007.

16. Pakistan. Ministry of Science and Technology. Council of Research in Water Resources. [cited 2016 Oct 04]. Available from: http://www.pcrwr.gov.pk/

17. Pappas G. Pakistan and water: new pressures on global security and human health. Am J Pub Health 2011;101:786-8.

18. van Zyl WB, Page NA, Grabow WO, Steele AD, Taylor MB. Molecular epidemiology of group A rotaviruses in water sources and selected raw vegetables in southern Africa. Appl Environ Microbiol. 2006;72:4554-60.

19. Gutiérrez-Aguirre I, Steyer A, Boben J, Gruden K, PoljsakPrijatelj M, Ravnikar M. Sensitive detection of multiple rotavirus genotypes with a single reverse transcription-realtime quantitative PCR assay. J Clin Microbiol. 2008;46:254754

20. He XQ, Cheng L, Zhang DY, Li W, Xie XM, Ma M, et al. First molecular detection of group A rotaviruses in drinking water sources in Beijing, China. Bull Environ Contam Toxicol. 2009;83:120-4.

21. Gutiérrez MF, Alvarado MV, Martínez E, Ajami NJ. Presence of viral proteins in drinkable water sufficient condition to consider water a vector of viral transmission? Water Res. 2007;41:373-8.

22. Dongdem JT, Adjimani J, Armah G. Detection and characterization of human rotavirus in tap water by multiplex RT-PCR. J Med Med Sci. 2010;1:223-30.

23. Glass RI, Kilgore PE, Holman RC, Jin S, Smith JC, Woods PA, et al. The epidemiology of rotavirus diarrhea in the United States: surveillance and estimates of disease burden. J Infect Dis. 1996;174:S5-11.

24. Konno T, Suzuki H, Katsushima N, Imai A, Tazawa F, Kutsuzawa T, et al. Influence of temperature and relative humidity on human rotavirus infection in Japan. J Infect Dis. 1983;147:125-8.

25. Bresee J, Fang ZY, Wang B, Nelson EA, Tam J, Soenarto Y, et al. First report from the Asian Rotavirus Surveillance Network. Emerg Infect Dis. 2004;10:988-95. 
26. Bishop RF, Masendycz PJ, Bugg HC, Carlin JB, Barnes GL. Epidemiological patterns of rotaviruses causing severe gastroenteritis in young children throughout Australia from 1993 to 1996. J Clin Microbiol. 2001;39:1085-91.

27. Cook SM, Glass RI, LeBaron CW, Ho MS. Global seasonality of rotavirus infections. Bull World Health Organ. 1990;68:171-7.

28. Ansari SA, Springthorpe VS, Sattar SA. Survival and vehicular spread of human rotaviruses: possible relation to seasonality of outbreaks. Rev Infect Dis. 1991;13:448-61.

29. Ozçelik S, Co kun KA, Yünlü O, Alim A, Malatyal E. The prevalence, isolation and morphotyping of potentially pathogenic free-living amoebae from tap water and environmental water sources in Sivas. Turkiye Parazitol Derg. 2012;36:198-203.

30. Leiva B, Clasdotter E, Linder E, Winiecka-Krusnell J. Free-living Acanthamoeba and Naegleria spp. amebae in water sources of León, Nicaragua. Rev Biol Trop. 2008;56:439-46.

31. Alotaibi MA. Internalisation of enteric viruses by Acanthamoeba castellanii, via ingestion of virus-infected mammalian cells. Food Environ Virol. 2011;3:109-14. 